\begin{tabular}{|c|}
\hline 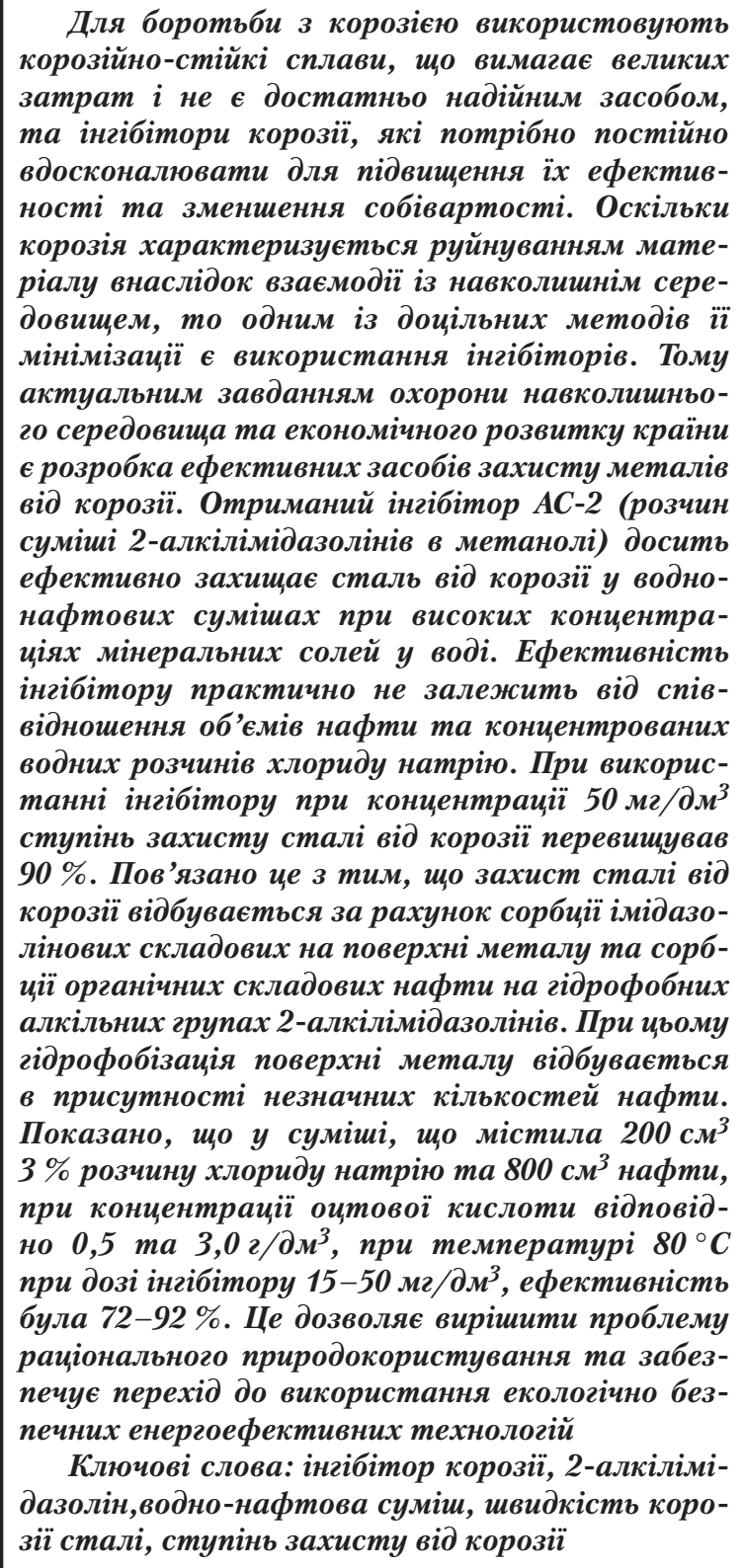 \\
\hline
\end{tabular}

UDC 628.168 .3

DOI: $10.15587 / 1729-4061.2020 .199849$

\section{DEVISING A CORROSION INHIBITOR FOR STEEL ST37-2 IN A WATER-OIL MIXTURE}

Received date 03.02.2020

Accepted date 24.03.2020

Published date 30.04.2020
Copyright (C) 2020, N. Gomelya, I. Trus, O. Stepova, O. Kyryliuk, O. Ivanenko, A. Khomenko This is an open access article under the CC BY license (http://creativecommons.org/licenses/by/4.0)

\section{Introduction}

Despite the significant development of industrial synthetic substances production, metals remain the main structural material that is indispensable in a series of industries. Given the increase in the volume of metal production, there is an enhanced need to protect them against corrosion [1]. It is worth noting that most domestic oil pipelines are operated under conditions of intensive internal corrosion; the operation of wells is associated with the release of mineral particles, in particular sand, which also leads to the wear of the equipment. High corrosion activity at oil extraction is the feature of water from mines as it is characterized by high mineralization $[2,3]$. Crude oil causes the corrosion of steel pipelines since it is heated to a temperature of $80{ }^{\circ} \mathrm{C}$ and contains up to $30 \%$ of water when it is pumped [4]. One of the common resource-saving methods of ensuring safe operation of pipelines and increasing their durability is the use of anticorrosive protection. The anticorrosive protection of elements, which are exposed to corrosive influence, is an integral part of the operation of oil pipelines that ensure the uninterrupted functioning of the oil industry equipment and an important element of the environmental safety of production. The most effective method of eliminating corrosion influence is the use of corrosion inhibitors [5,6]. A permanent monitoring of the corrosion condition of pipelines makes it possible to quickly take measures to protect them against corrosion, determine the service life of the equipment, and perform the repair works in time [7]. 
Therefore, it is a relevant area of research to find effective corrosion inhibitors in order to reduce corrosion aggressiveness of water-oil mixtures depending on their oil-mineral composition and to define the optimal parameters.

\section{Literature review and problem statement}

It is known that in mineralized waters the best inhibitors are those of the adsorption type, which are capable of adsorbing in the form of a thin film at the metal surface, thereby significantly reducing the rate of metal oxidation when interacting with water [8].

The authors of work [9] investigated the influence of the $d$-metals ions in the composition with phosphonic acids on the processes of corrosion in a neutral aqueous medium. It was shown that a series of ions, such as zinc, chromium, lead, under high aeration conditions and a temperature of $20^{\circ} \mathrm{C}$ at concentrations $2-5 \mathrm{mg} / \mathrm{dm}^{3}$, are effective steel corrosion inhibitors. The degree of corrosion protection is maintained at $80-90 \%$. It was shown that phosphonic acids, such as oxyethylidene diphosphonic acid and nitrilotrimethylphosphonic acid, provide a degree of corrosion protection at the level of $95-98 \%$ at acid doses of up to $10 \mathrm{mg} / \mathrm{dm}^{3}$. At higher temperatures, there is a significant reduction of protective properties due to the destruction of a passivation film at the metal surface when the concentration of oxygen in water is reduced. Consequently, the main drawback of these inhibitors is the reduction of the protective effect at a temperature over $50{ }^{\circ} \mathrm{C}$.

An effective anti-corrosion agent for steel that is used in high-chloride water environments is the «green» organic compounds [10,11]. The maximum efficacy of inhibition of $94.6 \%$ was achieved using $500 \mathrm{ppm}$ of the inhibitor. However, the cited works $[10,11]$ considered the selective action only for a neutral water corrosive environment and did not study the efficacy of inhibitors for bi-phase systems that are characteristic of steel corrosion in the petrochemical and oil-refining industries.

It is known that the main components of corrosion inhibitors for the oil-industrial equipment are imidazolines. Imidazolines belong to the corrosion inhibitors of mixed type as they reduce the speed of the anode dissolving of iron and the cathodic reduction of hydrogen. As surfactants, imidazolines have the cation-active properties, are good emulsifiers, and form water-soluble salts. Film-forming and anticorrosion properties contribute to their use in industry as corrosion inhibitors. This is predetermined by that imidazolines adsorb at the metal-solution interface and contribute to the formation of a monomolecular hydrophobic layer that repels water, thereby slowing the rate of steel corrosion. The P110 inhibitor demonstrated an inhibition corrosion efficiency of $97.6 \%$ at a concentration of about $200 \mathrm{mg} / \mathrm{dm}^{3}$ [12].

At present, there are many known $\mathrm{N}-$, O-, S-containing organic compounds that have proven to be effective corrosion inhibitors for various aggressive environments. More effective for the water-saturated oil deposits saturated with $\mathrm{CO}_{2}$ is to use the derivatives of heterocyclic compounds, namely, azoles, imidazolines. Two new thiadiazole derivatives were synthesized and investigated as soft-alloy corrosion inhibitors in a water $\mathrm{CO}_{2}$ saturated oil deposit in paper [13]. It is shown that the corrosion protection efficiency is $98.7 \%$ even at a rather low concentration of $0.0025 \mathrm{mM} / \mathrm{dm}^{3}$, and reaches $99.37 \%$ at a concentration of $0.025 \mathrm{mM} / \mathrm{dm}^{3}$. The synthesized inhibitors reported in [14] demonstrate good steel cor- rosion indicators in the water of reservoir deposits saturated with $\mathrm{CO}_{2}$. It was determined that the degree of protection increased by increasing the polymer concentration to the maximum values of 92.12 and $96.52 \%$ for $150 \mathrm{ppm}$ at $50{ }^{\circ} \mathrm{C}$ in the presence of SR-16 and SR-17, respectively. The findings in [15] showed that the $\mathrm{N}$-, S-containing organic compounds could effectively protect carbon steel against corrosion, while the efficiency of inhibition increases as the concentration of the inhibitor grows, reaching $93 \%$ at $50 \mathrm{mg} / \mathrm{l}$. Even at a low concentration of $10 \mathrm{mg} / \mathrm{l}$, the density of corrosion current decreases from $1.447 \cdot 10^{-4} \mathrm{~A} \cdot \mathrm{cm}^{-2}$ for the model sample to $2.99 \cdot 10^{-5} \mathrm{~A} \mathrm{~cm}^{-2}$ after 12 hours of immersion. Paper [16] tackles the effectiveness of imidazoline derivatives as a corrosion inhibitor of steel J55 in the water of a reservoir oil field saturated with $\mathrm{CO}_{2}$. The effectiveness of inhibition is up to $90 \%$ at $400 \mathrm{mg} / \mathrm{l}$. The addition of an inhibitor reduces the density of anode current, as well as the anode current, and significantly enhances the parameters of electrochemical impedance spectroscopy. The efficiency of a soft steel corrosion inhibitor in a $1.0 \mathrm{M} \mathrm{HCl}$ solution with a temperature from $25^{\circ} \mathrm{C}$ to $90^{\circ}$ was $99.2 \%$ [17]. A major disadvantage of these inhibitors is the high prices for relatively significant expenditures in the corrosive environment [12-17]. Therefore, the unresolved issue is to devise effective affordable corrosion inhibitors for metals in water-organic environments.

Study [18] synthesized alkylimidazolines with the use of sunflower oil and diethylene triamine. However, if we consider that diethylene triamine price reaches USD 56/kg and the price of pure ethylenediamine is USD $48 / \mathrm{kg}$ while the consumption of ethylenediamine to produce $1 \mathrm{~kg}$ of imidazoline is $30 \%$ less, it would be advisable to perform the synthesis using ethylenediamine.

The issue of eliminating corrosion of steel, given a significant quantitative and qualitative range of solutions in the water-oil environment, is quite complicated and relevant. In addition, the ever-increasing requirements for environmental safety and economic feasibility of oil and gas equipment predetermine the search for more effective, less toxic, and cheap corrosion inhibitors. Therefore, studies are aimed at developing corrosion inhibitors that have a high protective effect. These inhibitors meet environmental and economic requirements and are widely available for industrial use.

\section{The aim and objectives of the study}

The aim of this study is to synthesize a new inhibitor that would effectively protect steel against corrosion in water-oil mixtures at high concentrations of mineral salts in water.

To accomplish the aim, the following tasks have been set:

- to determine the effectiveness of the synthesized imidazolines using EDA, depending on the ratio of the volumes of oil and the concentrated aqueous solutions of sodium chloride;

- to determine the rate of corrosion of St37-2 steel and to establish the optimum dose of the synthesized inhibitor $\mathrm{AC}-2$ in a water-oil mixture in the presence of acetic acid at a temperature of $80^{\circ} \mathrm{C}$.

\section{Synthesis and evaluation methods of the reagent AC-2 as a steel corrosion inhibitor in water-oil mixtures}

For the synthesis, a mixture of $50 \%$ of ethylenediamine (EDA) water solution with oil in Octanol 1 was used. 
We added to $950 \mathrm{~g}$ of oil $240 \mathrm{~g}$ of a $50 \%$ EDA solution and $500 \mathrm{~cm}^{3}$ of Octanol 1. The mixture, at stirring, was gradually heated to $190^{\circ} \mathrm{C}$ in a reactor, distilling water and an excess of amine with octanol impurities. After 6-hour heating, when the water ceased to distill, we distilled octanol in a vacuum. The remaining light-brown liquid, which, after the dissolution in methanol, was used as an inhibitor (AC-2). The water-amine-octanol mixture was distilled by sampling a fraction with a boiling point of $116^{\circ} \mathrm{C}$. The resulting aqueous solution of ethylenediamine, as well as the distilled Octanol 1 , is suitable for reuse. The resulting inhibitor is well-soluble in methanol, acetone, benzene, chloroform, and other solvents. Given that it was mainly used in the emulsions of water and oil, we selected methanol as a solvent. Excess ethylenediamine is required to prevent the formation of diamines of carboxylic acids, whose conversion into imidazolines requires maintaining high temperatures $\left(>300^{\circ} \mathrm{C}\right)$, which sharply reduces the yield of the main products.

The process of alkylimidazoline synthesis is implemented in two stages (Fig. 1).

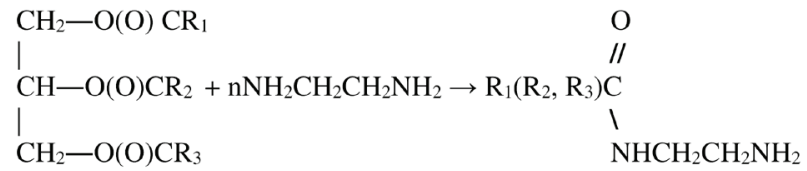

$\left.+\mathrm{CH}_{2} \mathrm{OHCHOHCH} \mathrm{OH}_{2} \mathrm{OH}-1\right) \mathrm{NH}_{2} \mathrm{CH}_{2} \mathrm{CH}_{2} \mathrm{NH}_{2}$<smiles>[R20][R16](=O)NCCN</smiles>

Fig. 1. The reaction of alkylimidazoline synthesis

The samples of steel St37-2 were used for the current work. Corrosion was studied by a gravimetric method. The corrosive environment used was a water-oil mixture (the ratio of oil to a $3 \%$ sodium chloride solution is $80: 20,20: 80$, $5: 95)$ and a mixture that contained $200 \mathrm{~cm}^{3}$ of a $3 \%$ sodium chloride solution, $800 \mathrm{~cm}^{3}$ oil at the concentration of acetic acid of 0.5 and $3 \mathrm{~g} / \mathrm{dm}^{3}$. The temperature was $80^{\circ} \mathrm{C}$. We changed the inhibitor concentration from 5 to $50 \mathrm{mg} / \mathrm{dm}^{3}$. Corrosion time is $8-10$ hours.

To confirm the reaction mechanism, we have synthesized 2-alkylimidazoline on the basis of ethylenediamine and enanthic acid in the Octanol 1 solution, under conditions identical to those when obtaining the inhibitor AC-2. The yield of imidazoline after the recrystallization from hexane is $69 \%$, so in a given case we received an individual product, rather than a mixture, in contrast to AC-2. The PMR spectrum was acquired and analyzed using the «TeslaBS-487s» spectrophotometer in $\mathrm{DCl}_{3}$ solution. The internal standard is GMDS.

The characteristics of the obtained 2-hexylimidazoline: The melting point $T_{m}=58{ }^{\circ} \mathrm{C}, \mathrm{PMR}, \sigma$, ppm: $0.80 \mathrm{t}\left(3 \mathrm{H} \mathrm{CH}_{3}\right)$, $J_{\mathrm{CCH}}=7.15 \mathrm{~Hz} ; 0.98-1.56 \mathrm{~m}\left(8 \mathrm{H} \mathrm{CH}_{2}\right) ; 2.01 \mathrm{t}\left(2 \mathrm{H} \mathrm{CH}_{2}\right)$; $J_{\mathrm{CCH}}=7.97 \mathrm{~Hz} ; 3.38 \mathrm{c}\left(4 \mathrm{H} \mathrm{CH}_{2}\right) ; 5.80 \mathrm{~s}(1 \mathrm{H} \mathrm{NH})$.

The steel samples of $2 \times 3 \mathrm{~cm}$ with a thickness of $1 \mathrm{~mm}$ were mechanically cleaned from corrosion products by grinding paper and sanded to metallic luster. Next, the metallic samples were degreased in ethanol, dried in a drying chamber at $90-100{ }^{\circ} \mathrm{C}$, and weighed on analytical scales with an accuracy of the fourth character.

Following the corrosion test, the St-37-2 samples were cleaned from petroleum products in a solution of ethanol, aged for 30 minutes in $0.5 \%$ sulfuric acid in the presence of urotropine $\left(C=10 \mathrm{~g} / \mathrm{dm}^{3}\right)$. Next, the corrosion products were completely removed by rubber, the samples were washed in ethanol and dried in a drying chamber. After that, we reweighed them with the accuracy of the fourth character.

The corrosion rate and corrosion protection level were calculated from formulae [18].

$$
\begin{aligned}
& V=\frac{m_{1}-m_{2}}{S \cdot t}, \mathrm{~g} /\left(\mathrm{m}^{2} \cdot \mathrm{h}\right), \\
& Z=\left(1-\frac{V_{i}}{V_{0}}\right) \cdot 100 \%,
\end{aligned}
$$

where $m_{1}$ is the initial mass, $\mathrm{g} ; m_{2}$ is the sample weight after the experiment, $\mathrm{g} ; S$ is the surface area of the steel samples, $\mathrm{m}^{2}$; $t$ is the time of an experiment, h; $V_{i}, V_{0}$ is the corrosion rate of steel with and without an inhibitor, $\mathrm{g} /\left(\mathrm{m}^{2} \cdot \mathrm{h}\right)$.

\section{Results of studying the inhibitor effectiveness}

5.1. Determining the effectiveness of the synthesized imidazolines using EDA (AC-2)

Our study determined the efficacy of the inhibitor synthesized in the condensation of oil with ethylenediamine (AC-2). Fig. 2 shows that a given inhibitor was quite effective in a water-oil mixture with a volumetric share of oil of $80 \%$ and a $3 \%$ solution of $\mathrm{NaCl} 20 \%$. In the absence of acid in the mixture, even at $80^{\circ} \mathrm{C}$, the rate of corrosion of steel St $37-2$ was relatively small and reached $0.3191 \mathrm{~mm} /$ year. The inhibitor was used in concentrations from 5 to $50 \mathrm{mg} / \mathrm{dm}^{3}$. When using the AC-2 inhibitor, the protection level reached $88 \%$ at a concentration of $5 \mathrm{mg} / \mathrm{dm}^{3}$. At $25 \mathrm{mg} / \mathrm{dm}^{3}$, the degree of protection exceeded $90 \%$.

High was the efficacy of the inhibitor in a water-oil mixture medium containing in $1 \mathrm{dm}^{3} 800 \mathrm{~cm}^{3} 3 \%$ of the solution $\mathrm{NaCl}$ and $200 \mathrm{~cm}^{3}$ of crude oil (the ratio of oil to water in the mixture was $2: 8$ ). At a temperature of $80^{\circ} \mathrm{C}$, the degree of protection against corrosion of steel St37-2 at a concentration of the inhibitor of $5 \mathrm{mg} / \mathrm{dm}^{3}$ reached $66-68 \%$ (Fig. 3 ), and at $50 \mathrm{mg} / \mathrm{dm}^{3}$ the degree of protection for the inhibitor exceeded $90 \%$. A somewhat lower was the efficacy of the inhibitor in an environment that consisted of $95 \%$ of the solution of $3 \%$ sodium chloride and $5 \%$ of oil (Fig. 4).

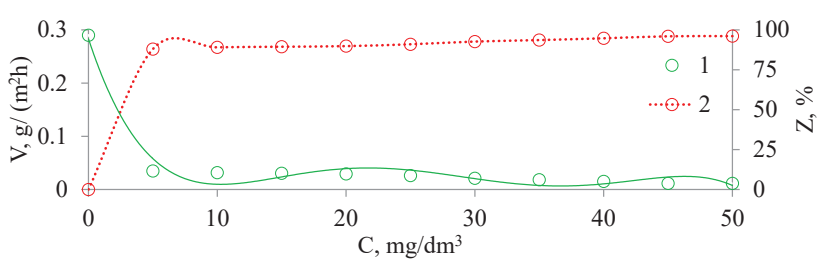

Fig. 2. Dependence of the characteristics of corrosion of steel St37-2 on the concentration of the AC-2 inhibitor at $80{ }^{\circ} \mathrm{C}$ in a water-oil mixture ( $80 \%$ oil and $20 \%$ of $3 \%$ solution $\mathrm{NaCl}$ ): 1 - rate of steel corrosion; 2 - degree of protection against corrosion; $y=-3.9 \cdot 10^{-08} x^{5}+$ $+5.604 \cdot 10^{-06} x^{4}-2.97258 \cdot 10^{-04} x^{3}+7.095380 \cdot 10^{-03} x^{2}-$

$-7.3801132 \cdot 10^{-02} x+0.283422395 ; R^{2}=0.97549$ 


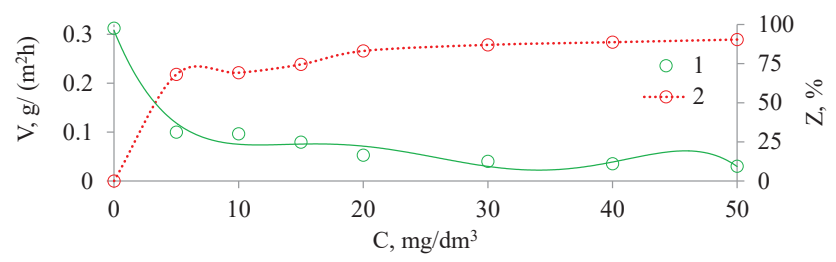

Fig. 3. Dependence of the characteristics of corrosion of steel St37-2 on the concentration of the AC-2 inhibitor at $80{ }^{\circ} \mathrm{C}$ in the environment of a water-oil mixture

( $20 \%$ oil and $80 \%$ of $3 \%$ solution of $\mathrm{NaCl}$ ): 1 - rate of corrosion of steel St37-2; 2 - degree of protection against corrosion; $1: y=-4.25 \cdot 10^{-08} x^{5}+$ $+5.73 \cdot 10^{-06} x^{4}-2.818479 \cdot 10^{-04} x^{3}+6.2268652 \cdot 10^{-03} x^{2}-$ $-6.26596094 \cdot 10^{-02} x+0.3078147804 ; R^{2}=0.97846$

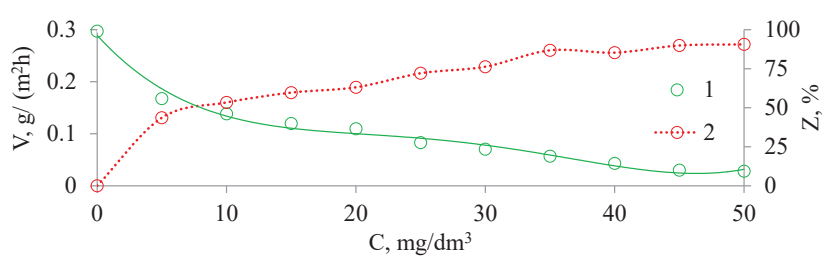

Fig. 4. Dependence of the characteristics of corrosion of steel St37-2 on the concentration of the AC-2 inhibitor at $80{ }^{\circ} \mathrm{C}$ in the environment of a water-oil mixture ( $5 \%$ oil and $95 \%$ of $3 \%$ solution of $\mathrm{NaCl}$ ): 1 - rate of corrosion of steel St37-2; 2 - degree of protection against corrosion; $1: y=-1.5 \cdot 10^{-08} x^{5}+$ $+2.225 \cdot 10^{-06} x^{4}-1.20930 \cdot 10^{-04} x^{3}+2.989695 \cdot 10^{-03} x^{2}-$ $-3.616078 \cdot 10^{-02} x+0.294878 ; R^{2}=0.98681$

In this case, at a concentration of the inhibitor of $5 \mathrm{mg} / \mathrm{dm}^{3}$, the degree of protection of steel St37-2 against corrosion for the AC-2 inhibitor was $43.6 \%$. At a concentration of $50 \mathrm{mg} / \mathrm{dm}^{3}$, the degree of protection of steel against corrosion reached $90 \%$.

5. 2. Determining the efficacy of the synthesized AC-2 inhibitor in a water-oil mixture in the presence of acetic acid

Further study determined the efficacy of the AC-2 reagent in acetic acid-containing environments. Thus, the mixture that contained $200 \mathrm{~cm}^{3}$ of a $3 \%$ sodium chloride solution and $800 \mathrm{~cm}^{3}$ of oil at the concentration of acetic acid, respectively, of 0.5 and $3 \mathrm{~g} / \mathrm{dm}^{3}$ at a temperature of $80^{\circ} \mathrm{C}$ demonstrated quite high efficacy of the inhibitor. At the concentration of acetic acid of $0.5 \mathrm{~g} / \mathrm{dm}^{3}$ for a dose of the inhibitor of $10 \mathrm{mg} / \mathrm{dm}^{3}$, the corrosion rate decreased from 1.6 to $0.7 \mathrm{~g} / \mathrm{m}^{2} \cdot \mathrm{h}$ (Fig. 5 ).

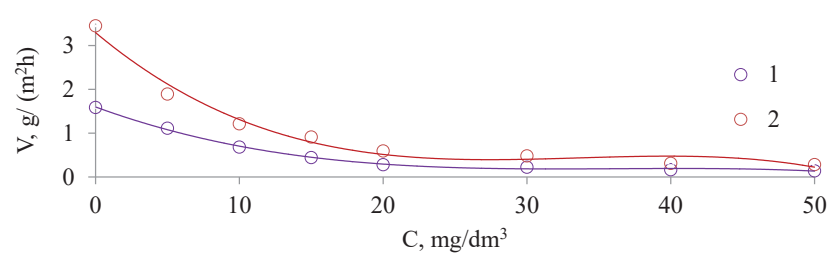

Fig. 5. Dependence of the rate of corrosion of steel St37-2 on the concentration of the AC-2 inhibitor in a water-oil mixture: $1-0.5 \mathrm{~g} \mathrm{CH}_{3} \mathrm{C}(\mathrm{O}) \mathrm{OH}$;

$2-3.0 \mathrm{~g} \mathrm{CH}_{3} \mathrm{C}(\mathrm{O}) \mathrm{OH} ; 1: y=-3 \cdot 10^{-05} x^{3}+0.00334 x^{2}-$ $-0.11979 x+1.59891 ; R^{2}=0.999778$;

2: $y=-8 \cdot 10^{-05} x^{3}+0.00846 x^{2}-0.27474 x+3.29281$; $R^{2}=0.98247$
The degree of protection against corrosion under these conditions reached $56-57 \%$ (Fig. 6). At a concentration of the inhibitor at the level of $50 \mathrm{mg} / \mathrm{dm}^{3}$, the degree of protection reached $90-91 \%$. The high results were also obtained with the use of the AC-2 inhibitor in a mixture of water and oil containing $3 \mathrm{~g} / \mathrm{dm}^{3}$ of acetic acid. At the inhibitor doses of $10-50 \mathrm{mg} / \mathrm{dm}^{3}$, the degree of corrosion protection of steel St37-2 reached $64-92 \%$.

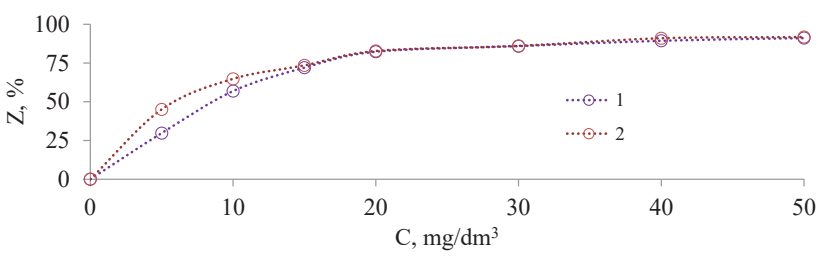

Fig. 6. Dependence of the degree of protection against corrosion of steel St37-2 on the concentration of the AC-2

inhibitor in a water-oil mixture: $1-0.5 \mathrm{~g} \mathrm{CH}_{3} \mathrm{C}(\mathrm{O}) \mathrm{OH}$; $2-3.0 \mathrm{~g} \mathrm{CH}_{3} \mathrm{C}(\mathrm{O}) \mathrm{OH}$

Thus, we can argue that the synthesized inhibitors based on oil and ethylenediamine containing imidazolines are not inferior, in terms of quality, to the best-known inhibitors of steel corrosion in water-oil mixtures.

6. Discussing the results of the process of synthesis and estimation of the effectiveness of the AC-2 inhibitor (a mixture of 2-alkylimidazolines)

It is known that the synthesis processes of 2-alkylimidazolines, when using relatively cheap ethylenediamine and carboxylic acids, are implemented rather inefficiently. This is because carboxylic acids, when mixed with EDA, form ammonium salts on both amine groups, regardless of the excess of amine. Another issue is the fact that when an EDA mixture with carboxylic acids is heated at a temperature of $>116^{\circ} \mathrm{C}$ the EDA azeotrope passes, along with water, into a steam phase. This results in that the excess of amine in the reaction zone is hard to with the basic product of the process being the thermally resistant diamides of EDA and carboxylic acids. When the latter transform to imidazolines, they must be heated to $400{ }^{\circ} \mathrm{C}$. It is obvious that this significantly increases energy costs for the process. In addition, a large part of the products decomposes at high temperatures, which considerably reduces the yield of the main product, which, even at the perfect implementation of the process, cannot theoretically exceed $50 \%$ of the amount of the used carboxylic acid.

The processes occur better when using the esters of carboxylic acids. However, given the high price of the higher carboxylic acids and the costs on its esterification, obtaining imidazolines in this way could prove to be too expensive.

Much cheaper is to use oil, especially technical fractions, which are much cheaper than carboxylic acids. In addition, oils are a complex ether of carboxylic acids and glycerin. Therefore, when mixing it with EDA, ammonium salts do not form. Furthermore, the formation of EDA amides and carboxylic acids when using the esters of the latter proceeds much easier, at lower temperatures, than when applying pure acids. That is, the first stage of the process can be implemented at temperatures below $100^{\circ} \mathrm{C}$ with the excess of EDA in the reaction mixture. This contributes to the formation of mostly monoamides that can easily condense with the formation of imidazolines. 
The formation of monoamides and imidazolines is also contributed to by the use of a solvent - Octanol 1. This is primarily preventing the formation of diamides. In addition, octanol makes it possible to maintain the temperature in a reactor at the level of $190{ }^{\circ} \mathrm{C}$, regardless of excessive EDA and the amount of water. Water is easily distilled in the form of azeotrope from the reaction zone, which assists in the acceleration of the process of formation of monoamide and the acceleration of its cyclization to imidazoline.

In general, when conducting reactions in solutions, the intramolecular transformations proceed better when the concentration of the solution is lower.

The high product yield is also contributed to by the use of oil in which carboxylic acids have organic radicals $\mathrm{C}_{16}-\mathrm{C}_{20}$. This creates steric barriers to attack the free ammonium group of EDTA monoamide and glycerol ester carboxylic acid.

Judging by the ratio of signals in the PMR spectra of the product in the region of $3.4 \mathrm{ppm}$ (the protons of $\mathrm{CH}_{2}$ groups of the imidazoline ring) with the intensity of signals of alkyl groups, it can be said that in a given case (with a five-fold excess of EDA), there occurs an almost full conversion of oil to imidazoline. The inhibitor itself, given that the oil molecules contain the components of various carboxylic acids, mainly consists of a mixture of 2-alkylimidazolines (Fig. 7).<smiles>[R]C1=NCNN1</smiles>

$\mathrm{H}$<smiles>[R]C1=NCN1</smiles>

$\mathrm{H}$

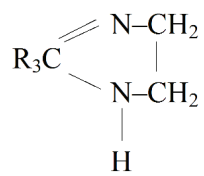

$\mathrm{H}$
Fig. 7. A mixture of 2-alkylimidazolines included in the composition of $\mathrm{AC}-2$

At a temperature of $80^{\circ} \mathrm{C}$, the degree of protection against the corrosion of steel at a concentration of the inhibitor of $50 \mathrm{mg} / \mathrm{dm}^{3}$ exceeded $90 \%$ (Fig. 2-4). The efficiency of the AC-2 reagent in acetic acid-containing environments amounted to $92 \%$ (Fig. 5, 6).

Since in the water-oil mixtures the best inhibitors are those based on imidazoline, we chose the $\mathrm{AC}-1$ inhibitor for comparison, which is quite close to the resulting inhibitor AC-2. The synthesis of the AC-1 inhibitor involved diethylenetriamine, which is much more expensive than ethylenediamine, which was used for the synthesis of the AC-2 inhibitor. At the concentration of acetic acid of $0.5 \mathrm{~g} / \mathrm{dm}^{3}$ at a dose of the inhibitor $\mathrm{AC}-1$ of $50 \mathrm{mg} / \mathrm{dm}^{3}$ the corro- sion rate decreased from 1.5872 to $0.1583 \mathrm{~g} /\left(\mathrm{m}^{2} \cdot \mathrm{h}\right)[18]$; when using the AC-2 inhibitor, this indicator decreased to $0.1412 \mathrm{~g} /\left(\mathrm{m}^{2} \cdot \mathrm{h}\right)$. When using the inhibitor in a water and oil mixture containing $3 \mathrm{~g} / \mathrm{dm}^{3}$ of acetic acid, the corrosion rate decreased from $3.4508 \mathrm{~g} /\left(\mathrm{m}^{2} \cdot \mathrm{h}\right)$ without the inhibitor to $0.3015 \mathrm{~g} /\left(\mathrm{m}^{2} \cdot \mathrm{h}\right)$ when using the $\mathrm{AC}-1$ inhibitor in the amount of $50 \mathrm{mg} / \mathrm{dm}^{3}$ [18] and to $0.2845 \mathrm{~g} /\left(\mathrm{m}^{2} \cdot \mathrm{h}\right)$ when using the AC-2 inhibitor (Fig. 5). Thus, it can be concluded that the inhibitor synthesized in the current work is more efficient and cheaper.

The advantage of a given inhibitor is the fact that 2-alkylimidazolines at elevated temperatures are easily distilled with petroleum products and water vapors. Therefore, they can be used not only in oil transportation but also at its processing.

This study addressed the effectiveness of the steel corrosion inhibitor AC-2 only, at a temperature of $80^{\circ} \mathrm{C}$. It is important to investigate and to determine the effectiveness of the synthesized inhibitor at higher temperatures. Therefore, the subject of further research is to study the effectiveness of the developed steel corrosion inhibitor AC-2 at elevated temperatures $\left(100-400^{\circ} \mathrm{C}\right)$ in the steam-gas phase with the impurities of water vapor. That would make it possible to use the inhibitor both in oil pipelines and in the technological processes of oil refining.

\section{Conclusions}

1. It has been shown that the imidazoline-based inhibitors are quite effective in the water-oil mixtures. We have devised a method to synthesize alkylimidazolines on the basis of oil and ethylenediamine in the octanol solution, which makes it possible to obtain highly effective corrosion-resistant steel inhibitors in water-oil mixtures at the high concentrations of mineral salts in the water. The effectiveness of the inhibitor almost does not depend on the ratio of the volumes of petroleum and the concentrated aqueous solutions of sodium chloride. At a concentration of the inhibitor of $50 \mathrm{mg} / \mathrm{dm}^{3}$, the degree of protection of steel against corrosion reached $90-92 \%$.

2. It has been established that the efficiency of the AC-2 reagent in acetic acid environments is rather high. At a dose of the inhibitor of $10 \mathrm{mg} / \mathrm{dm}^{3}$ at a temperature of $80^{\circ} \mathrm{C}$, the degree of corrosion protection reached $57-65 \%$, while increasing the dosage of the inhibitor to $15-50 \mathrm{mg} / \mathrm{dm}^{3}$ increases the protection degree to $72-92 \%$.

\section{References}

1. Vasyliev, G., Brovchenko, A., Herasymenko, Y. (2013). Comparative Assessment of Corrosion Behaviour of Mild Steels 3, 20 and 08KP in Tap Water. Chemistry \& Chemical Technology, 7 (4), 477-482. doi: https://doi.org/10.23939/chcht07.04.477

2. Gomelya, N. D., Trus, I. N., Nosacheva, Y. V. (2014). Water purification of sulfates by liming when adding reagents containing aluminum. Journal of Water Chemistry and Technology, 36 (2), 70-74. doi: https://doi.org/10.3103/s1063455x14020040

3. Trus, I. M., Fleisher, H. Y., Tokarchuk, V. V., Gomelya, M. D., Vorobyova, V. I. (2017). Utilization of the residues obtained during the process of purification of mineral mine water as a component of binding materials. Voprosy Khimii i Khimicheskoi Tekhnologii, 6, 104-109.

4. Rajasekar, A. (2016). Biodegradation of Petroleum Hydrocarbon and Its Influence on Corrosion with Special Reference to Petroleum Industry. Environmental Footprints and Eco-Design of Products and Processes, 307-336. doi: https://doi.org/10.1007/ 978-981-10-0201-4_9

5. Khalaf, M. M., Tantawy, A. H., Soliman, K. A., Abd El-Lateef, H. M. (2020). Cationic gemini-surfactants based on waste cooking oil as new «green» inhibitors for N80-steel corrosion in sulphuric acid: A combined empirical and theoretical approaches. Journal of Molecular Structure, 1203, 127442. doi: https://doi.org/10.1016/j.molstruc.2019.127442 
6. Vasyliev, G., Vorobiova, V. (2019). Rape grist extract (Brassica napus) as a green corrosion inhibitor for water systems. Materials Today: Proceedings, 6, 178-186. doi: https://doi.org/10.1016/j.matpr.2018.10.092

7. Vasyl'ev, H. S., Herasymenko, Y. S. (2017). Corrosion Meters of New Generation Based on the Improved Method of Polarization Resistance. Materials Science, 52 (5), 722-731. doi: https://doi.org/10.1007/s11003-017-0015-9

8. Tantawy, A. H., Abo-Riya, M. A., Abdallah, S. M., El-Dougdoug, W. (2018). Novel cationic surfactants based on waste frying oil for cleaning water surface from petroleum films: Synthesis, antimicrobial and surface properties. Journal of Molecular Liquids, 253, 36-44. doi: https://doi.org/10.1016/j.molliq.2018.01.009

9. Shabliy, T., Nosachova, J., Radovenchik, Y., Vember, V. (2017). Study of effectiveness of heavy metals ions as the inhibitors of steel corrosion. Eastern-European Journal of Enterprise Technologies, 4 (12 (88)), 10-17. doi: https://doi.org/10.15587/ 1729-4061.2017.106974

10. Vorobyova, V. I., Skiba, M. I., Trus, I. M. (2019). Apricot pomaces extract (Prunus Armeniaca L.) as a highly efficient sustainable corrosion inhibitor for mild steel in sodium chloride solution. International Journal of Corrosion and Scale Inhibition, 8 (4), 1060-1084. doi: https://doi.org/10.17675/2305-6894-2019-8-4-15

11. Vorobyova, V., Chygyrynets', O., Skiba, M., Trus, I., Frolenkova, S. (2018). Grape Pomace Extract as Green Vapor Phase Corrosion Inhibitor. Chemistry \& Chemical Technology, 12 (3), 410-418. doi: https://doi.org/10.23939/chcht12.03.410

12. Liang, M., Miao, J. (2013). Corrosion inhibition behavion of an iimidazoline inhibitor for P110 steel. Corrosion and Protection, 4 (5), 395-398.

13. Zhang, Q. H., Hou, B. S., Xu, N., Liu, H. F., Zhang, G. A. (2019). Two novel thiadiazole derivatives as highly efficient inhibitors for the corrosion of mild steel in the CO2-saturated oilfield produced water. Journal of the Taiwan Institute of Chemical Engineers, 96, 588-598. doi: https://doi.org/10.1016/j.jtice.2018.11.022

14. Al-Shihry, S. S., Sayed, A. R., Abd El-lateef, H. M. (2020). Design and assessment of a novel poly(urethane-semicarbazides) containing thiadiazoles on the backbone of the polymers as inhibitors for steel pipelines corrosion in CO2-saturated oilfield water. Journal of Molecular Structure, 1201, 127223. doi: https://doi.org/10.1016/j.molstruc.2019.127223

15. Cen, H., Chen, Z., Guo, X. (2019). N, S co-doped carbon dots as effective corrosion inhibitor for carbon steel in $\mathrm{CO}_{2}$-saturated $3.5 \%$ $\mathrm{NaCl}$ solution. Journal of the Taiwan Institute of Chemical Engineers, 99, 224-238. doi: https://doi.org/10.1016/j.jtice.2019.02.036

16. Singh, A., Ansari, K. R., Lin, Y., Quraishi, M. A., Lgaz, H., Chung, I.-M. (2019). Corrosion inhibition performance of imidazolidine derivatives for J55 pipeline steel in acidic oilfield formation water: Electrochemical, surface and theoretical studies. Journal of the Taiwan Institute of Chemical Engineers, 95, 341-356. doi: https://doi.org/10.1016/j.jtice.2018.07.030

17. Lei, X., Wang, H., Feng, Y., Zhang, J., Sun, X., Lai, S. et. al. (2015). Synthesis, evaluation and thermodynamics of a 1H-benzo-imidazole phenanthroline derivative as a novel inhibitor for mild steel against acidic corrosion. RSC Advances, 5 (120), 99084-99094. doi: https://doi.org/10.1039/c5ra15002g

18. Gomelya, N., Trus, I., Stepova, O., Kyryliuk, O., Hlushko, O. (2020). Synthesis of high-effective steel corrosion inhibitors in water-oil mixtures. Eastern-European Journal of Enterprise Technologies, 1 (6 (103)), 6-11. doi: https://doi.org/10.15587/ 1729-4061.2020.194315 